\title{
Blasimon à Mouliets-et-Villemartin
}

\section{Marie-Christine Gineste}

\section{OpenEdition \\ Journals}

Édition électronique

URL : http://journals.openedition.org/adlfi/7879

ISSN : 2114-0502

Éditeur

Ministère de la culture

Référence électronique

Marie-Christine Gineste, « Blasimon à Mouliets-et-Villemartin », ADLFI. Archéologie de la France -

Informations [En ligne], Aquitaine, mis en ligne le 01 mars 2007, consulté le 03 mai 2019. URL : http:// journals.openedition.org/adlfi/7879

Ce document a été généré automatiquement le 3 mai 2019.

(c) Ministère de la Culture et de la Communication, CNRS 


\title{
Blasimon à Mouliets-et-Villemartin
}

\author{
Marie-Christine Gineste
}

Identifiant de l'opération archéologique : 025265

Date de l'opération : 2007 (EX)

1 La construction d'une canalisation de transport de gaz naturel DN 900 entre Captieux et Mouliets-et-Villemartin est à l'origine de ce diagnostic archéologique articulé en une prospection pédestre sur l'emprise des travaux - une bande de $10 \mathrm{~m}$ - et des sondages archéologiques sur le tracé de la conduite. Ce diagnostic correspond à la phase IV des travaux, de Blasimon à Mouliets-et-Villemartin.

2 La sensibilité archéologique de toute la vallée entre le Pas de Rauzan sur la Dordogne et le plateau de l'entre-deux-mers à Blasimon est confirmée par la mise au jour d'un patrimoine archéologique particulièrement riche pour les périodes protohistorique - âge du Bronze et âge du Fer - et médiévale.

3 Deux points d'occupation de l'âge du Bronze ancien ou moyen, distants d'environ $200 \mathrm{~m}$, ont été reconnus à Mouliets-et-Villemartin, sur le lieu-dit « aux Cumères » et à Pujols, « la Fantaisie », non loin du ruisseau du Romédol.

4 L'indice de « la Fantaisie » repose sur la découverte dans un sondage d'une concentration de mobilier, remarquable par sa facture et son degré de conservation dans un contexte sédimentaire où aucun aménagement n'a pu être distingué. Ce regroupement de céramiques correspond à au moins quatre jattes, dont deux à décor incisé similaire : trois lignes parallèles et horizontales soulignent la lèvre ; au-dessous se développe une frise de petites lignes verticales incisées. Les vases à décor incisé paraissent recouverts d'un engobe rouge. Un fond de vase polypode appartenait à cet ensemble, ainsi que quelques fragments d'un autre fond de même type.

5 En l'absence de tout indice d'incinération, la raison du regroupement de ces vases, particulièrement soignés comparativement aux autres découvertes de Mouliets-etVillemartin attribués à la même période reste inexpliquée. Cette découverte indique 
cependant la proximité d'un site dont les témoins structurés ne sont pas apparus dans le cadre du diagnostic.

6 L'occupation intensive du territoire de Mouliets-et-Villemartin pendant le second âge du Fer est illustrée, en dehors de "Lacoste", par une série de fossés au lieudit "à la route ", à environ $250 \mathrm{~m}$ au sud de " Lacoste », puis encore $400 \mathrm{~m}$ plus au sud, « au Barry " où se pratiquait une activité d'extraction, révélée par la découverte de fosses de plusieurs mètres de diamètre.

7 Sur les mêmes secteurs, la période médiévale est également très représentée : au lieu-dit «à la route », par des fosses et un fossé du XI ${ }^{\mathrm{e}}$ s.-XIII ${ }^{\mathrm{e}}$ s., et « au Barry » au travers d'une batterie de silos de datation similaire.

8 Sur la commune de Bossugan, à $80 \mathrm{~m}$ à l'est de l'église paroissiale, le site important de «Bordieu », reflet d'une occupation depuis le haut Moyen Âge jusqu'au bas Moyen Âge, s'étire sur une centaine de mètres sur un replat en pied de plateau. Il correspond à une exploitation agricole, caractérisée notamment par des silos en périphérie. Au centre, deux groupes de trous de poteaux ont été reconnus, définissant des espaces couverts dont la fonction reste ici indéterminée, en l'absence de tout foyer ou sol conservé. Ce site a également livré une inhumation d'adulte ou de subadulte et une structure en creux contenant les vestiges incomplets de deux périnataux.

9 Sur le territoire de « Ruch », à « Baron », une vaste fosse dépotoir témoigne par la qualité de la céramique et la découverte d'un couteau dague de la proximité d'une riche habitation du XIV ${ }^{\mathrm{e}} \mathrm{s}$.

10 À Blasimon, des indices mobiliers du bas Moyen Âge ont été recensés au lieu-dit « Grange Guitard».

11 Les traces d'occupation du Paléolithique et du Néolithique sont plus ponctuelles. Un peu d'industrie lithique attribuée au Paléolithique a été découverte sur le plateau de Blasimon, à " Mounet », et à « Grange Guitard », en bas de pente.

12 Sur la commune de Saint-Pey-de-Castets, au lieu-dit "Champ de Claire», une forte concentration de céramique néolithique dont des fragments de gros vases de stockage a révélé la proximité d'un site remanié par les crues de l'Escouach voisin.

13 L'absence d'indice structuré pour la période gallo-romaine est à noter, sans que cela soit significatif compte tenu de l'étroitesse de notre bande d'observation.

INDEX

operation Expertise (EX)

Index chronologique : âge du Bronze, âge du Fer, Moyen Âge, Néolithique, Paléolithique

Thèmes : céramique du bronze, céramique néolithique, couteau, exploitation agricole, fosse, fossé, fosse-dépotoir, habitation, industrie lithique, inhumation, silo, trou de poteau

Index géographique : Aquitaine, Gironde (33), Blasimon 
AUTEURS

MARIE-CHRISTINE GINESTE

INRAP 